\title{
Blood Wettability of Haemocompatible Carbon-based Materials
}

Torrisi $L^{*}$ and Scolaro C

Department of Mathematical and Informatics Sciences, University of Messina, Messina, Italy

*Corresponding author: Torrisi L, Department of Mathematical and Informatics Sciences, University of Messina, Messina, Italy, Tel: 090 6765052; E-mail: lorenzo.torrisi@unime.it

Received date: October 10, 2017; Accepted date: October 23, 2017; Published date: October 25, 2017

Copyright: () 2017 Torrisi L, et al. This is an open-access article distributed under the terms of the Creative Commons Attribution License, which permits unrestricted use, distribution, and reproduction in any medium, provided the original author and source are credited.

\begin{abstract}
The carbon haemocompatible substrates represent an important group of biomaterials due to their possibility to be used in direct contact with the blood for long times without produce thrombus and dysfunctions of the blood flow in which the biomaterial is immersed. Between the different materials used, the carbon assumes a very significant role for its high capacity of haemocompatibility and physical properties. The wet ability to some biological liquids and blood in different biocompatible material surfaces is investigated for comparison with carbon based surfaces and to distinguish hydrophilic from hydrophobic behaviours. The interest concerns materials based on carbon actually used mainly in orthopedic, dental and cardiovascular applications. A relation between wetting ability and surface roughness is studied to optimize the case of high hydrophilic, employable for cell adhesion and growth, from high hydrophobic characteristics, useful for blood flow vessels and for parts of mobile prosthesis.
\end{abstract}

Keywords: Blood; Carbon; Haemocompatible substrates; Wetting ability; Biomaterials

\section{Introduction}

The use of biomaterials for prosthesis realization in recent decades has had a high development for many different applications, from orthopaedics to cardiology and from ophthalmology to dentistry [1]. This development was possible thanks to the strong increase in knowledge about the interactions between living organisms and inert or active biomaterials [2]. A biomaterial must be able to interact with the tissues and perform the functions for which it was designed without produce tissue damaging and inflammation in the time. Among the effects of the biomaterial in a biological environment, of particular interest is that due to materials which are in contact with the blood. Among these, in fact, in the first place it is important to consider the alteration of coagulation factors, the nature of the material in direct contact with the blood and its influence on the speed of blood coagulation. As soon as the blood comes in contact with a foreign material, the first clinically evident process that occurs is the activation of haemostasis. This involves coagulation, blood changing from a liquid to a gel. The endothelial cells of intact vessels prevent blood clotting with a heparin-like molecule and thrombomodulin and prevent platelet aggregation with nitric oxide and prostacyclin [3].

So the use of appropriate surface becomes useful for improving the biocompatibility with the blood and the consequent biological response that determines its long-term in vivo use. Not only the nature but also the surface morphology of the biomaterials plays important role from the point of view of the wetting ability with liquids. For example for the mechanical valve prostheses, in contact with the blood, must be chosen the haemocompatible carbon and its surface must be very smooth to facilitate the blood low with low hydrodynamical resistance and to avoid dangerous micro- and macro-metric thrombotic formations [4]. Attempts to use bio-materials based on carbon for the production of implantable devices in different positions and critical organs, particularly in cardiovascular prostheses, date back to the beginning of bioengineering.
Carbon exhibits excellent biocompatibility properties with tissues and has optimal characteristics of mechanical resistance, density and elasticity, similarity with many tissues and can be processed to be used as thick or thin films in different types of prostheses [5]. Carbon has many allotropic forms: amorphous, crystalline, diamond, graphene, graphite, polycrystalline, glassy carbon, partially crystalline and pyrolytic carbon. In diamond state it is sp3 hybridized and carbon atoms are bounded together into a set of tetrahedral shape. The diamond like carbon (DLC) is one of the most attractive blood contacting biomaterials, for instance, in artificial heart valves, stents, and rotary blood pumps because of its high inertness and excellent mechanical properties. DLC consists of an amorphous form of the carbon containing both graphitic type bonding (sp2) and diamond type tetragonal bonding (sp3). In graphite state carbon atoms are bound together in planar fashion, constitute a graphene, i.e., a set of adjacent hexagons arranged on a plane. Almost all materials based on carbon used in biomedical applications have a structure crystalline or near-crystalline. The glassy carbon, for example, is represented by carbon obtained by thermal treatments at high temperature $(\sim 3000$ ${ }^{\circ} \mathrm{C}$ ) of organic substances, in particular polymers, such as cellulose or phenolic resins, and they can be shaped with the desired shape. Really the glassy carbon is not composed exclusively of $\mathrm{C}$ atoms, such as graphite, since the heat treatment leads to a partial oxidation of $\mathrm{C}$ atoms with formation of functional groups of various natures [6]. The pyrolytic carbon is a material of great interest in the cardiovascular field for its high compatibility with the blood; it is a material similar to graphite, but with some covalent bonding between its graphene sheets as a result of imperfections in its production. It is produced by heating a hydrocarbon nearly to its decomposition temperature, permitting the graphite to crystallize (pyrolysis) [7]. The process can be based on synthetic fibres heating in a vacuum or to place seeds or a plate in the very hot gas to collect the graphite coating. The deposition technology allows obtaining a piece of graphite coated by a deposit of pyrolytic carbon often less than $1 \mu \mathrm{m}$ in thickness. The presence inside the deposit of pyrolytic carbon of very hard carbides, increases the mechanical properties of the deposit itself, in particular increases the 
Page 2 of 6

hardness and the wear resistance while the mechanical friction decreases.

The use of carbon in biomaterials to realize prosthesis occurs in many cases, from the diamond-like films for orthopaedic, to pyrolytic films to cover cardiac valves and from carbon fibres to promote osteoblast adhesion to graphite to reduce the wear and friction in mobile prosthesis.

Many surface properties are fundamental for their use as part of prosthesis, such as morphology, roughness, hardness, wear, mechanical, thermal and electrical properties, gas diffusivity and chemical reactivity. In this work the wettability and the roughness of the biocompatible surfaces were investigated. In particular the contact angle of different biological liquids, from which blood, on different types of carbon surfaces, used in orthopaedic, dental and cardiovascular applications, was measured and correlated with the surface roughness.

\section{Materials and Methods}

Different inorganic biomaterials have been selected for the characterization of the wettability of human blood and physiological fluids: Silica $\left(\mathrm{SiO}_{2}\right.$, amorphous, $10 \times 8 \times 1 \mathrm{~mm}$ plates), Alumina
$\left(\mathrm{Al}_{2} \mathrm{O}_{3}\right.$, gamma structure, $10 \times 8 \times 1 \mathrm{~mm}$ plates), Titanium (Ti, pure, grade 2, $20 \mathrm{~mm}$ diameter, $2 \mathrm{~mm}$ thickness disks), Steel (316L, $15 \mathrm{~mm}$ diameter, $2 \mathrm{~mm}$ thickness disks), Niobium (Nb pure, $20 \mathrm{~mm}$ in diameter, $1 \mathrm{~mm}$ thickness), Polyethylene (PE, $15 \times 15 \times 1 \mathrm{~mm}$ plates), Polymethylmethacrylate (PMMA, $10 \times 5 \times 2 \mathrm{~mm}$ plates) and Polystyrene (PS, $15 \times 15 \times 1 \mathrm{~mm}$ plates).

Wettability was measured also in haemocompatible carbon-based materials, such as Diamond-Like Carbon (DLC, $3.5 \mathrm{~g} / \mathrm{cm}^{3}, 20 \times 50$ $\mathrm{mm}^{2}$ surface $\times 2$ microns thickness), High Density Ultra-Pure Carbon (HDUPC, $3 \mathrm{~g} / \mathrm{cm}^{3}, 70 \times 50 \mathrm{~mm}^{2}$ surface $\times 2$ micron thickness), Graphene $(5 \times 10 \mathrm{~mm}$ surface and $1 \mu \mathrm{m}$ thickness $)$, Graphite $(20 \times 20 \times$ $5 \mathrm{~mm}$ plates), Glassy Carbon $\left(20 \times 10 \mathrm{~mm}^{2}\right.$ surface $\times 1 \mathrm{~mm}$ thickness $)$ and Pyrolytic Carbon $(10 \times 10 \times 1 \mathrm{~mm}$ plates $)$. DLC was prepared as thin film by plasma deposition technique [6], HDUPC was deposited by DC magnetron sputtering technique [8], glassy carbon was prepared starting from a resin converted thermally and chemically in glassy carbon microstructures [6] and pyrolytic carbon containing silica traces has been prepared by the high temperature pyrolysis of copolyimides [7]. Some physical parameters of the different carbon materials, such as density, elastic modulus, compressive strength and toughness are reported in Table 1.

\begin{tabular}{|l|l|l|l|l|l|}
\hline & Types of Carbon & \multicolumn{4}{l|}{} \\
\hline Properties & Graphite & Glassy Carbon & Pyrolytic Carbon & Graphene & DLC \\
\hline Density $\left(\mathbf{g} / \mathbf{c m}^{3}\right)$ & $1.5-1.9$ & 1.5 & $1.5-2.0$ & 2.2 & 3.5 \\
\hline Elastic modulus (GPa) & 24 & 24 & 28 & 60 & 87 \\
\hline Compressive strength (MPa) & 138 & 172 & $517-575$ & 1500 & 900 \\
\hline Toughness $\left(\mathbf{m N} / \mathbf{c m}^{3}\right)$ & 6.3 & 0.6 & 4.8 & 20 & 30 \\
\hline
\end{tabular}

Table 1: Some physical properties of different types of carbon.

The wet ability was measured using four different body fluids: human blood, water, physiologic saline solution and vitamin E ( $a$ tocopherol acetate) solution. The contact angle measurements were carried out according to the "sessile drop" technique, consisting in the measure of the contact angle, $\theta$, between the tangent to the profile of a liquid drop deposited on the sample surface, and the surface itself, as depicted in inset of Figure 3 [9]. When $\theta$ is higher than $90^{\circ}$ the surface is hydrophobic, while it is hydrophilic when the angle is less than $90^{\circ}$.

The physiologic saline solution was obtained by dissolving $18 \mathrm{~g}$ of $\mathrm{NaCl}$ in $50 \mathrm{ml}$ of distilled water. The blood considered for this experiment is human blood taken from a healthy volunteer; it was taken in a laboratory of clinical analyzes and then stored in the original sterile tube (BD Vacutainer K3E) with $5.4 \mathrm{mg}$ Ethylenediaminetetraacetic acid (EDTA) at a temperature between $2^{\circ} \mathrm{C}$ and $6^{\circ} \mathrm{C}$. The liquid solution of EDTA binds calcium ions thus inhibiting the coagulation cascade, preserving the blood. In order to avoid the possible deterioration of blood, the measurements of contact angle were performed within 5 days from donation. Before the experiment, the tube was agitated to homogenise the solution and for a long time, until the room temperature was reached [10]. The Vitamin E solution, $\alpha$-tocopherol acetate, $\mathrm{C}_{31} \mathrm{H}_{52} \mathrm{O}_{3}$, is of BioChemika, purity $97 \%$. Temperature measurements for this study were obtained using Sika Electronic digital thermometer (TS 9180). At a temperature of $\mathrm{T}=22^{\circ} \mathrm{C}$.
A relative humidity $(\mathrm{RH})=35 \%$, and at $\mathrm{P}=1 \mathrm{~atm}$, with the calibrated syringe, were filed gently drops of liquids test of $(1 \mu \mathrm{l})$ on the horizontal face and perfectly flat of the sample.

The three used fluids were physically characterized by density, surface tension and viscosity at room temperature $\left(22^{\circ} \mathrm{C}\right)$. The density of the solutions were measured by weighing a known volume drop taken by a syringe and using an electronic microbalance (Kern KB 120-3N, $\max 121 \mathrm{~g}, \quad \mathrm{~d}=0.0001 \mathrm{~g})$. Ten independent weight measurements were taken and averaged.

The surface tension measurements were performed by the method of the dropper. The measurements were carried out at room temperature and relative humidity (of $\mathrm{T}=22^{\circ} \mathrm{C}$, H.R. $=35 \%$, respectively), by dripping slowly from a dropper of radius of $1.2 \mathrm{~mm}$, liquids test, on the electronic microbalance by determining the average weight of 15 drops.

The density, surface tension and viscosity of the blood depend on the hematocrit $(\mathrm{Ht})$ of the healthy volunteer [11]. In our measurements Ht value was of $39.3 \%$.

The measurements of viscosity of the distilled water were performed at $22^{\circ} \mathrm{C}$ by using a glass pipe and measuring the time of outflow of a known value of the solution concentration. The viscosity of our used liquids was $1.00 \mathrm{cPo}, 0.985 \mathrm{cPo}, 3.49 \mathrm{cPo}$ and $5000 \mathrm{cPo}$ for the water, 
saline solution, blood and vitamine E solution, respectively. Some physical properties of the liquids test used in our investigations, such the density and the surface tension, are summarized in the Table 2.

\begin{tabular}{|l|l|l|l|}
\hline \multirow{2}{*}{ Liquids } & Density & Surface tension & Viscosity \\
\cline { 2 - 4 } & {$\left[\mathbf{k g} / \mathbf{m}^{\mathbf{3}}\right]$} & {$\left[\mathbf{1 0}^{-3} \mathbf{~ N} / \mathbf{m}\right]$} & {$[\mathbf{c P o}]$} \\
\hline Whole Blood & 1054 & 62 & 3.49 \\
\hline Saline Solution & 1063 & 77 & 0.985 \\
\hline a-Tocopherol Acetate (Vitamin E) & 950 & 388 & 5000 \\
\hline Distilled Water & 997.8 & 72.22 & 1 \\
\hline
\end{tabular}

Table 2: Some physical properties of liquids used for wet ability measurements at $22^{\circ} \mathrm{C}$.

Six measurements of contact angle on drops of liquids test on different points of each sample were performed; subsequently the average value was calculated. The contact angle measurements reproducibility is affected by an indetermination $\Delta \theta= \pm 2^{\circ}$.

The roughness measurements of the different biomaterials were performed using a Tencor P-10 surface profiler having a micrometric scanning tip with $1 \mathrm{mg}$ force with a settable scansion length $(1 \mu \mathrm{m}-5$ $\mathrm{mm}$ ) and a sensitivity of $1 \mathrm{~nm}$ in depth and $1 \mu \mathrm{m}$ laterally [12].

The analysis is performed using a diamond tip that sweeps the surface of the specimen to follow the profile. A transducer converts the movement of the tip in electrical signal relative to the value of height profile. The surface roughness was measured using the average peakto-peak distance of the roughness profile.

\section{Results and Discussion}

The surface roughness profiles of some biomaterials used in orthopaedic and dentistry are shown in the Figure 1. They are referred to metals, ceramics and polymer with the following order: stainless steel $314 \mathrm{~L}(\mathrm{SS})$, titanium (Ti), titanium dioxide $\left(\mathrm{TiO}_{2}\right)$, alumina $\left(\mathrm{Al}_{2} \mathrm{O}_{3}\right)$, silica $\left(\mathrm{SiO}_{2}\right), \quad$ polystyrene (PS, $\left.\left(\mathrm{C}_{8} \mathrm{H}_{8}\right) \mathrm{n}\right)$ polymethylmethacryate (PMMA, $\left.\left(\mathrm{C}_{5} \mathrm{O}_{2} \mathrm{H}_{8}\right)_{\mathrm{n}}\right)$ and polyethylene $\left(\mathrm{PE},\left(\mathrm{CH}_{2}\right)_{\mathrm{n}}\right)$. The measured average roughness was 0.031 $\mu \mathrm{m}, 0.045 \mu \mathrm{m}, 0.08 \mu \mathrm{m}, 0.15 \mu \mathrm{m}, 0.23 \mu \mathrm{m}, 0.082 \mu \mathrm{m}, 0.03 \mu \mathrm{m}$ and 0.87 $\mu \mathrm{m}$ in the eight cases, respectively.

The wetting ability of human blood on these substrates was evaluated using the optical microscope equipped with CCD camera and software suitable to evaluate the contact angle. Figure 2 reports the images of the blood drop ( $1 \mu \mathrm{l}$ in volume) on the eight different biomaterial surfaces. The measured average contact angle was $61^{\circ}$, $56^{\circ}, 136^{\circ}, 75^{\circ}, 40^{\circ}, 65^{\circ}, 73^{\circ}$ and $61^{\circ}$, for steel, titanium, titanium dioxide, alumina, silica, polystyrene, polymethylmethacrylate and polyethylene, respectively. Thus, many surfaces appear hydrophylic with a different grade, except the $\mathrm{TiO}_{2}$ which is very hydrophobic.

Figure 3 reports the contact angle vs. the roughness for the different materials and the full plot doesn't show a regular trend due to the different nature of the investigated surfaces. However, by considering material groups with similar physical properties, such as the metals, the polymers and the ceramics, a regular trend appears, in facts for these three groups of materials seems that the contact angle decreases with the roughness, according to literature [13]. Thus results indicate that, in similar materials, the high roughness favours the hydrophilic action.

We analyze now the results referred to substrates based on haemocompatible carbon. Figure $4 \mathrm{a}$ shows the picture of the blood wettability of the 4 substrates of different carbons: High Density UltraPure (HDUP) Carbon, Graphite, Glassy Carbon and Pyrolytic Carbon. It is possible to observe that the contact angle is $24.09^{\circ}$, $79.16^{\circ}, 86.18^{\circ}$ and $101^{\circ}$ in the four cases, respectively. DLC appears similar to HDUP wettability. Thus, the best hydrophylic case is that obtainable using the DLC and HDUP carbon surfaces, having high roughness surface which improves the wet ability, while the best hydrophobic case is that obtainable using the pyrolytic carbon surface and the graphene, near specular.

The roughness profiles in the above described four carbon substrates are reported in Figure $4 \mathrm{~b}$. The measured average roughness is $5 \mu \mathrm{m}, 3.9 \mu \mathrm{m}, 3.0 \mu \mathrm{m}$ and $0.09 \mu \mathrm{m}$ in the HDUP, graphite, glassy carbon and pyrolytic carbon, respectively. DLC shows roughness similar to HDUP. The hydrophobic surface of glassy carbon is similar (but little less) to that of pure graphene and monocristallyne diamond. However measurements demonstrate that using graphene oxide or graphene rich in defects the wetting ability of the material increases significantly.

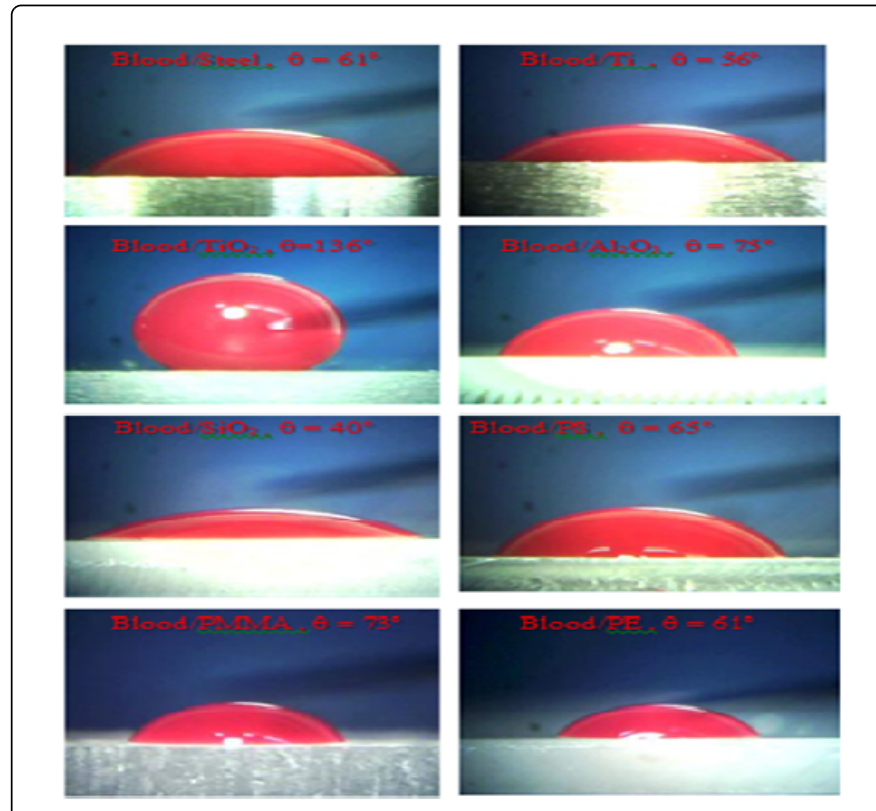

Figure 1: Typical surface profiles of biocompatible stainless steel (SS), Titanium (Ti), Titanium oxide $\left(\mathrm{TiO}_{2}\right)$, Alumina $\left(\mathrm{Al}_{2} \mathrm{O}_{3}\right)$, Silica $\left(\mathrm{SiO}_{2}\right)$, Polystyrene (PS), Polymethylmethacrylate (PMMA) and Polyethylene (PE).

The pyrolytic substrate shows a very mirror surface characterized by high hydrophobicity, an aspect very important for the optimal liquid flow in contact with this kind of solid surface. The comparison between the results reported in Figure $4 \mathrm{a}$ and $4 \mathrm{~b}$ permits developing the plot of the blood contact angle versus the carbon surface roughness, as reported in Figure 5. This plot indicates that the contact angle of the blood decreases with the roughness increment, as expected and in agreement with the literature [13], however it shows a nonlinear trend in the investigated carbon surfaces. 

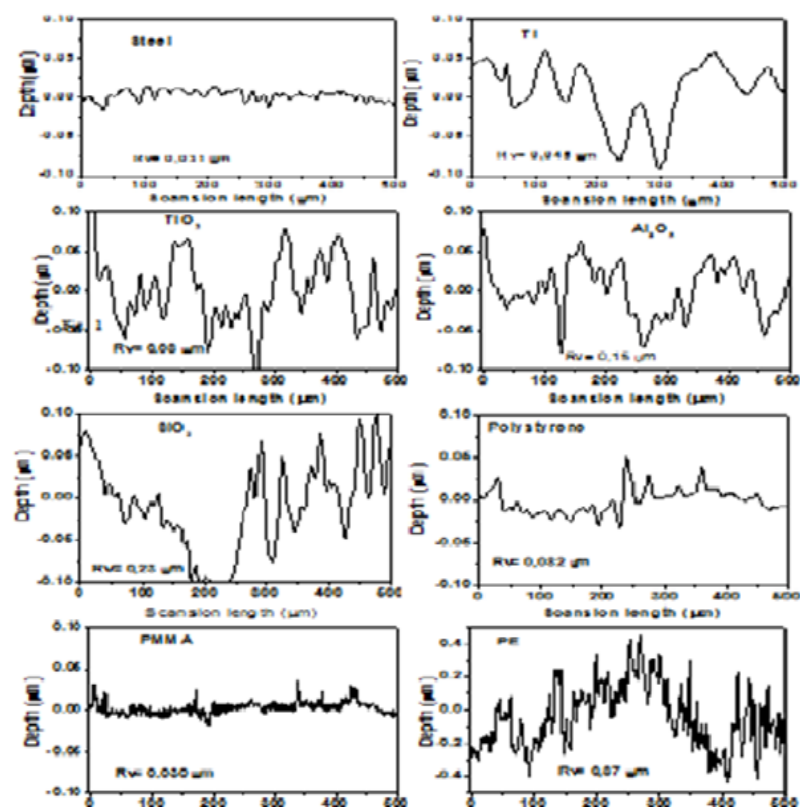

Figure 2: Typical contact angles of blood drop on different biocompatible surfaces: $\mathrm{SS}, \mathrm{Ti}, \mathrm{TiO}_{2}, \mathrm{Al}_{2} \mathrm{O}_{3}, \mathrm{SiO}_{2}$, PS, PMMA and PE.

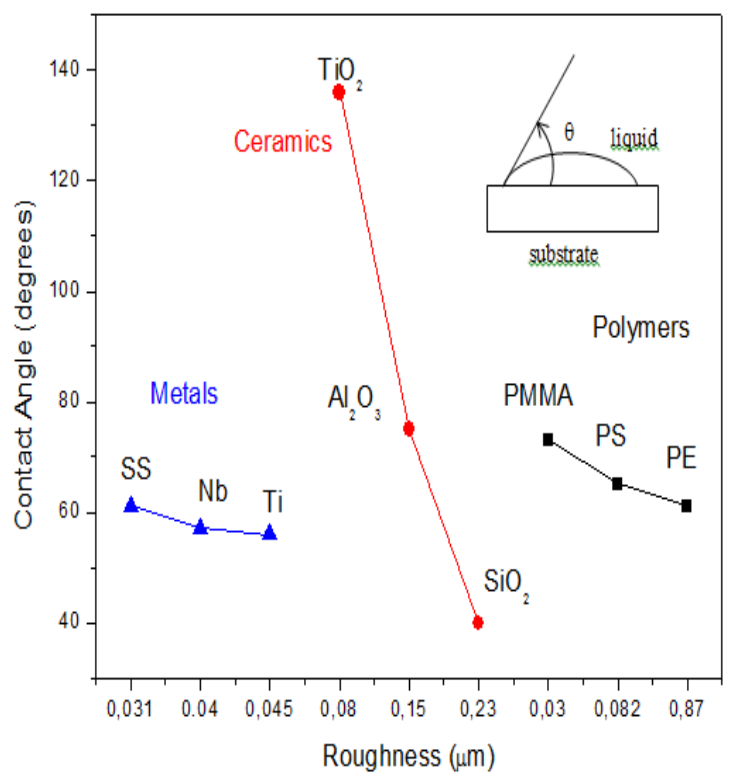

Figure 3: Blood contact angles vs. roughness of different biocompatible surfaces grouped in metals, ceramics and polymers. The inset shows a scheme of the sessile drop measurements.
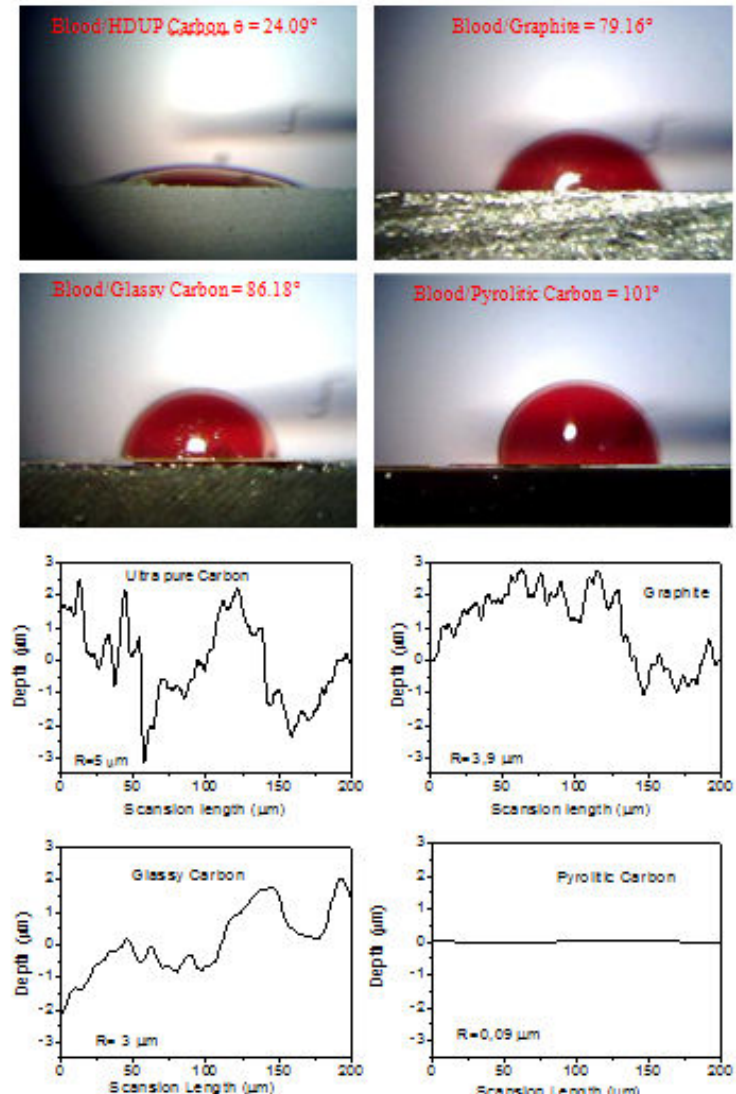

Figure 4: Typical contact angles of blood drop on four different haemocompatible carbon surfaces: high density ultra-pure (HDUP) carbon, graphite, glassy carbon and pyrolitic carbon (four top images) and relative surface roughness profiles (four bottom plots).

The mathematical relation between the contact angle $\theta$ (degrees) and the roughness $\mathrm{R}$ (microns) is the following:

$$
\theta=-1.58 . e^{-(R /-1.28)}+102.69
$$

This empirical law indicates that high contact angles can be obtained only at low surface roughness and very low contact angles above a near threshold value of about 4 microns for biocompatible carbons. This result permits to select the haemocompatible carbon surfaces depending on its use, that should have high hydrophilic action, such as the high density pure carbon, useful to act as adhesion substrate for living cells that must be anchored to the carbon surface with high adhesion forces, and high hydrophobic action, such as the pyrolytic carbon, and also crystallyne graphene and diamond, that shows negligible adhesion forces on the blood, facilitating its sliding and maintain low the surface wettability. In other words, for example, the HDUP carbon surface may be employed as cell culture substrate to growth cells, fibroblasts colonization and biological tissues [14], while the pyrolytic and graphene carbon surface may be useful, for example, as inner walls of artificial blood vessels with low hydrodynamic drag or to cover the surface of mobile devices, such as valves, to avoid the cell growth on its surface and to maintain low the friction coefficient $[15,16]$. 


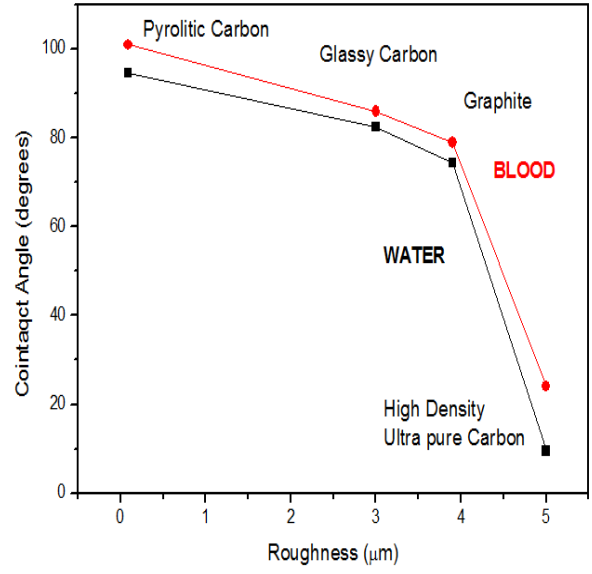

Figure 5: Blood and water contact angle vs. carbon surface roughness comparisons for four investigated haemocompatible surfaces.

The analyses of the wetting ability of blood on different carbon surfaces, roughness depending, have been performed also using other solutions, such as water, physiological solutions and solutions containing vitamin E. For instance, Figure 6a reports some photos relative to the contact angle of water on the four kinds of haemocompatible carbon substrates. Also, the wetting ability of the water follows the trend of the blood being $9.51^{\circ}, 74.31^{\circ}, 82.38^{\circ}$ and $94.69^{\circ}$ the contact angle for high density ultrapure carbon, graphite, glassy carbon and pyrolytic carbon, respectively. These data for water are compared with those of blood reporting the contact angle vs. roughness and the trend appears the same, as depicted in Figure 5 .

The physiological saline solution shows wetting characteristics similar to blood, while the solution containing the Vitamin E has a different behavior, being very hydrophilic with many substrates. Figure $6 \mathrm{~b}$ shows some photos of the wetting ability of the Vitamin E solution with the four carbon substrates. In all cases the wetting ability is high being the contact angle within the minimum value of $26.89^{\circ}$ in pyrolytic carbon up to a maximum value of $50.73^{\circ}$ in HDUP carbon.

The variations of the wetting ability for the different type of carbon for the three biological liquids mainly investigated are compared with each other, as shows in the plot of Figure 7. This comparison shows that in general the blood, saline and vitamine E solutions have similar properties of wetting in different carbon surfaces, except in the high density ultra-pure carbon showing relative higher wetting for vitamine E instead than for pure water. In particular the liquid contact with pyrolytic carbon and with graphene and diamond monocrystal shows high hydrophobicity and therefore its surface is non-wettable compared to the other types of carbon surfaces. Instead, the carbon contact with the vitamine E solution, which is a liquid very dense and viscous, shows a trend of the wettability opposite with respect to water, blood and saline solution, resulting the most hydrophilic among all.
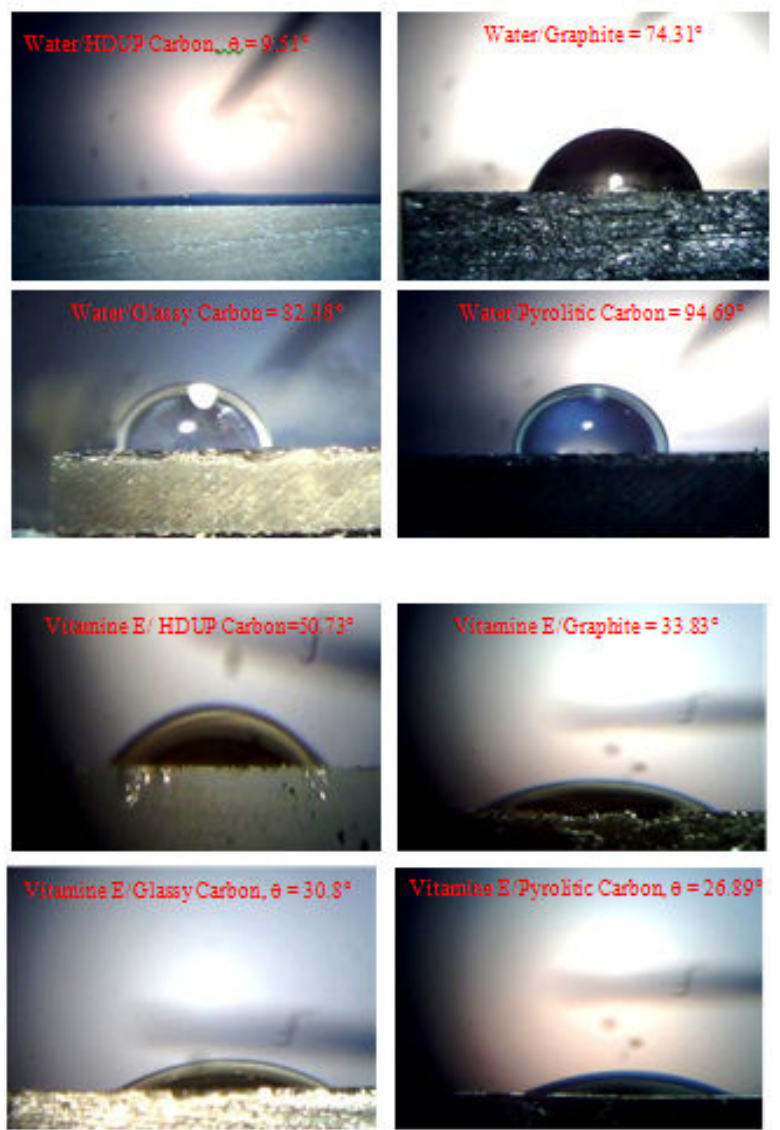

Figure 6: Water (top 4 photos) and Vitamine E solution (bottom 4 photos) contact angle vs. four carbon surfaces: HDUP, graphite, glassy carbon and pyrolitic carbon.

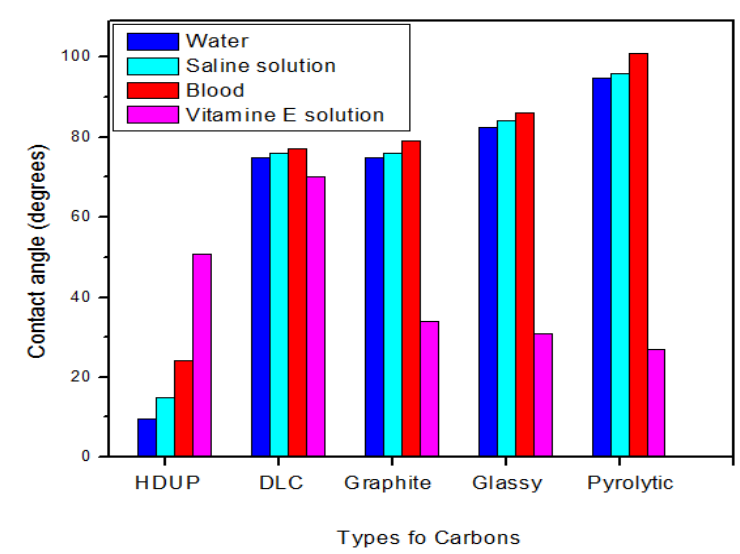

Figure 7: Comparison between the wetting contact angle for different carbon surfaces and for different biological liquids. 
Page 6 of 6

\section{Conclusions}

The surface roughness and wetting ability play an important role for biomaterials in contact with liquids, blood and living cells. The requisite of high hydrophylic action is important for materials in which cells must be anchored to the surface or two surfaces must be well adherent to generate a resistant and well welded interface. In recent years more and more different allotropic carbon surfaces are finding applications in many prosthesis types. DLC, glassy carbon and pyrolytic carbon films are assuming important role for long time devices in contact with blood or other fluids maintaining their requisite of biocompatibility, mechanical resistance and functionality, in respect to their optimized application. Also graphene foils are finding interesting applications to bio-medicine for its peculiar physical and chemical structural properties such as the mechanical resistance, the optical properties and the chemical reactivity. Graphene, for example, is employed for artificial retina implants, to treat diseases using electrical stimuli, graphene-based interfaces can deliver electrical signals intense enough to stimulate the human nervous system, to assist drug delivery and others [17,18], all applications were it is important the wetting ability of the conductive carbon foils.

Results indicated that a good hydrophilic carbon surface is that of HDUP carbon on which is expected that cells can have high adhesion yield. The requisite of high hydrophobic action, instead, is important for materials usable for artificial vessels, where the blood must flow easily without creating clots, and that of removable prosthesis at which the cells attachment must be prevented. Results indicates that a good hydrophobic carbon surface is that of pyrolytic carbon, in which is expected to have low cells adhesion and low wetting ability, a requisite useful for long life artificial blood haemocompatible vessels.

In this work is demonstrated that the use of haemocopatible carbon surfaces must be correlated to its nature and roughness. For haemocompatible surfaces on which cells must be very adherent is adapted a surface with high roughness, on the contrary, for surfaces in contact with liquid flow and for mobile prosthesis the wettability must be lower possible and the roughness as well.

The relation between contact angle and roughness is not linear such as in metals [13] but it follows an exponential law, as given by eq. (1), indicating high contact angles at low roughness and very low contact angles above a near threshold value of about 4 microns for biocompatible carbons.

In reference to the case of cardiovascular implants, in particular of cardiac valves, it is useful to make some considerations on the liquid interaction with the surface. The requested low wetting ability permits reducing the adsorption of the proteins, the formation of thrombi and coagulation maintaining a low hydrodynamical resistance of the liquid flow. The pyrolytic carbon is still the most biomaterial used in mechanical heart valves due to its properties of haemocompatibility, low roughness and hydrophobic action and to maintain for long time in the complex body environment these excellent properties, properties found also in the innovative graphene foils.

\section{Acknowledgements}

This research was supported by University of Messina Research \& Mobility 2016 Project (project code RES_AND_MOB_2016_TORRISI).

\section{References}

1. Basu B, Dhirendra K, Ashok K (2009) Advanced Biomaterials, Fundamentals, Processing, and Applications. J Wiley and Son Publ, USA.

2. Jan EE, Petter LS (2003) Bio-Implant Interface, Improving Biomaterials and Tissue Reactions. CRC Press, Boca Raton, New York, USA.

3. Marieb EN, Hoehn K (2010) Human Anatomy and Physiology 8th edn. San Francisco, Benjamin Cummings.

4. Webster JG (2006) Encyclopedia of medical devices and instrumentation, 2006, Wiley-Interscience, J Wiley and Sons, NewYork, USA.

5. Zhang M, Rajesh RN, Liming D (2016) Carbon Nanomaterials for Biomedical Applications. Springer, New York, USA.

6. Zakhidov AA, Baughman RH, Cui C, Dantas SO, Marti J, et al. (1998) Carbon Structures with Three-Dimensional Periodicity at Optical Wavelengths. Science 282: 897-901.

7. Pierson HO (1993) Handbook of Carbon, Graphite and Fullerenes, Properties, Processing and Applications, Noyes Publications, Park Ridge, New Jersey, USA.

8. Casiraghi C, Ferrari AC, Robertson J, Ohr R, Gradowski MV (2004) Ultra-thin carbon layer for high density magnetic storage devices. Diamond and Related Materials 13: 1480-1485.

9. Shang J, Flury M, Harsh JB, Zollars RL (2008) Comparison of different methods to measure contact angles of soil colloids. Journal of Colloid and Interface Science 328: 299-307.

10. Bowen RAR, Remaley AT (2014) Interferences from blood collection tube components on clinical chemistry assays. Biochem Med (Zagreb) 24: 31-44.

11. Stark H, Schuster S (2016) Comparison of various approaches to calculating the optimal hematocrit in vertebrates. Journal of Applied Physiology 113: 355-367.

12. Tencor KLA (2017) Stylus profiler, actual website: http://www.klatencor.com/Surface-Profiling/p-17.html.

13. Torrisi L, Scolaro C (2015) Treatment Techniques on Aluminum to Modify the Surface Wetting Properties. Acta Physica Polonica 128: 48-53.

14. Hu H, Ni Y, Mandal SK, Montana V, Zhao B, et al. (2005) Polyethyleneimine Functionalized Single-Walled Carbon Nanotubes as a Substrate for Neuronal Growth. J Phys Chem B Letters 109: 4285-4289.

15. Sharp WV, Teague PC, Scott DL (1978) Thromboresistance of pyrolytic carbon grafts Transactions. American Society for Artificial Internal Organs 24: 223-228.

16. Scolaro C, Torrisi L, Cutroneo M, Velardi L (2014) Wetting ability modifications in biocompatible polymers induced by pulsed lasers. Journal of Physics: Conference Series 508: 1-5.

17. Famm K, Litt B, Tracey KJ, Boyden E, Slaoui M (2013) Drug discovery: A jump-start for Electroceuticals. Nature 496: 159-161.

18. Kuila T, Bose S, Mishra AK, Khanra P, Kim NH, et al. (2012) Chemical functionalization of graphene and its applications. Progress in Materials Science 57: 1061-1105. 